\title{
PENERAPAN K3 BAGI PENAMBANG PASIR DI ALIRAN SUNGAI NOELMINA KECAMATAN BATUPUTIH KABUPATEN TIMOR TENGAH SELATAN PROVINSI NTT
}

\author{
Noni Banunaek ${ }^{1}$, Yusuf Rumbino ${ }^{2}$ \\ ${ }^{1,2}$ Prodi Teknik Pertambangan, Fakultas Sain dan Teknik, Universitas Nusa Cendana \\ ${ }^{1}$ nonibanynaek@gmail.com, ${ }^{2}$ yusufrumbino@staf.undana.ac.id
}

\begin{abstract}
CV. Talenalain is a company that mines sand without using excavators, but uses human labor and has a workforce of 25 people aged between 15 and 60 years. The Community Education Method is applied to increase workers' awareness of using PPE (personal protective equipment), understanding work hazards and diseases arising from sand mining activities. The material presented by the executive was about the benefits of PPE, handling minor incidental accidents, technical identification of hazards and diseases in the work environment. Apart from that, 25 sets of PPE equipment (helmets, gloves, rubber shoes, nose cover) were provided, 1 set of first aid kit, 1 set of warning signs, and several books on OHS Mining. The results of the activities of the implementation of Occupational Health and Safety (OHS) in the company can increase mining production by $20 \%$, discipline to use PPE increased by $80 \%$, increase in income of workers increased by $30 \%$. This shows that the improvement of the OHS system can increase overall company productivity.
\end{abstract}

Keyword: sand mine, hazard, diseases, OHS, PPE

\section{PENDAHULUAN}

Keberadaan sektor industri pertambangan yang berskala besar maupun yang berskala kecil akan memberi pengaruh dan perubahan terhadap kondisi sosial ekonomi masyarakat di sekitarnya karena terbukanya kesempatan kerja (Samsul 2018). Sektor pertambangan merupakan salah satu sumber pemasukan bagi Kabupaten Timor Tengah Selatan (TTS). Jenis-jenis bahan galian tambang di Kab. TTS adalah jenis bahan galian industri seperti batu gamping, marmer, kalsit dan pasir batu/sirtu (http://ttskab.go.id/potensi-daerah/pertambangan/). Salah satu jenis bahan galian yang banyak diusahakan oleh kelompok masyarakat adalah tambang pasir batu (sirtu) di aliran Sungai Noemina yang berada di Kabupaten Timor Tengah Selatan yang berjarak kurang lebih 70 km dari Kota Kupang (Gambar 1).

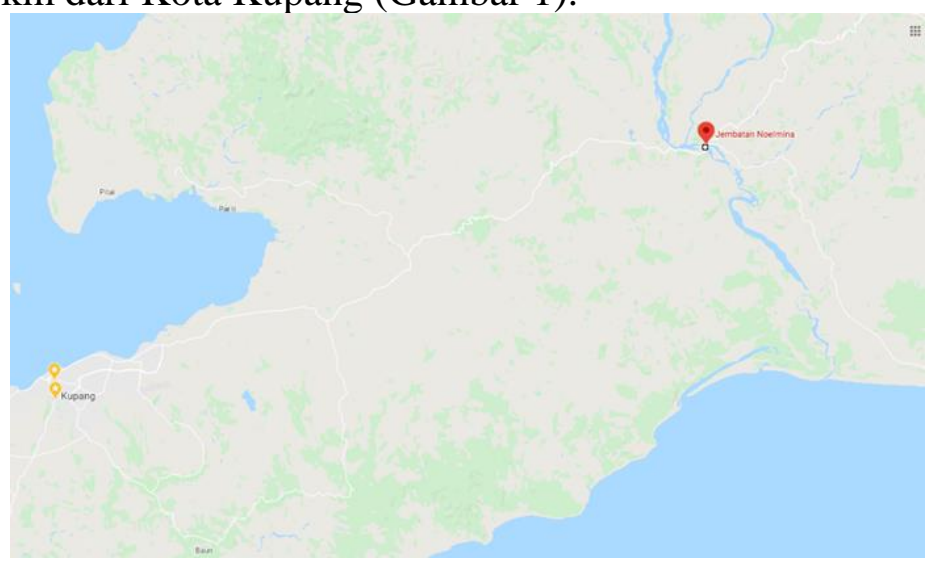

Gambar 1. Jarak Kota Kupang dengan Sungai Noelmina

(https://www.google.com/maps/place/Jembatan+Noelmina )

Penambangan di aliran Sungai Noelmina marak dilakukan karena pembangunan infrastruktur di Kota Kupang sebagian besar menggunakan pasir dan batu dari Wilayah Sungai Noelmina yang biasa disebut Pasir Takari. Pasir di wilayah ini memiliki agregat yang sesuai dengan kebutuhan campuran mortar, kandungan silika yang tinggi dan bersih dari lumpur pengotor (clay, silt). Pasir yang ditambang terlebih dahulu dicuci dan disaring menggunakan trommel screen (ayakan putar) atau menggunakan ayakan statis 
yang dipasang miring. Fungsi ayakan untuk menyingkirkan batuan dan kerikil yang berukuran lebih besar dari pasir.

Keberadaan usaha pertambangan ini tentunya membuka lapangan pekerjaan bagi masyarakat di sekitar sungai. Para pemilik tambang dengan modal besar melakukan penggalian dengan menggunakan alat ekscavator jenis backhoe (Gambar 2). Penggunaan alat muat backhoe dengan kapasitas sekitar 1,5 meter ${ }^{3}$ dapat mengisi truk dengan 4 kali swing, sehingga waktu yang dibutuhkan hanya sekitar 15 menit. Perusahaan ini biasanya memiliki pegawai berkisar 5 orang yang bertugas sebagai operator alat berat, pengawas lapangan dan pengatur antrian truk (dispatcher).

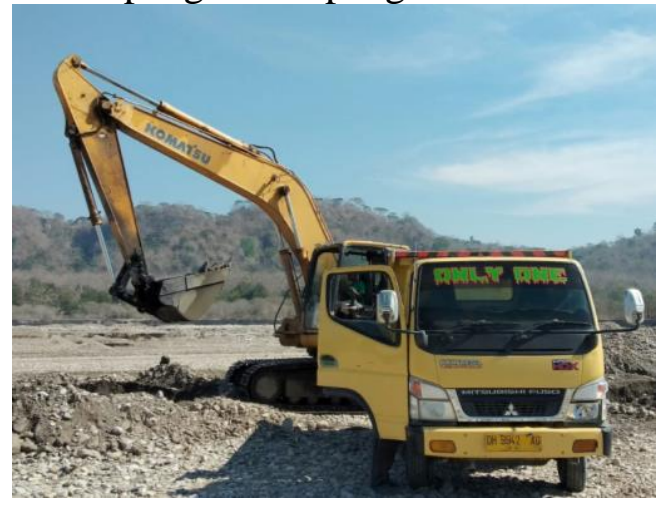

Gambar 2. Penambangan menggunakan peralatan mekanis

Pemilik tambang dengan modal kecil lebih memilih menggunakan tenaga manusia untuk menggali endapan pasir (Gambar 3) tentunya menggunakan pekerja lebih banyak yang mencapai 20 sampai 30 orang. Para pekerja ini menggali dan mengumpulkan pasir di sepanjang sungai, setelah truk pengangkut tiba maka mereka bersama-sama menaikkan pasir ke atas truk (Gambar 4). Tentunya diperlukan waktu yang lebih lama dibandingkan dengan menggunakan alat mekanis.

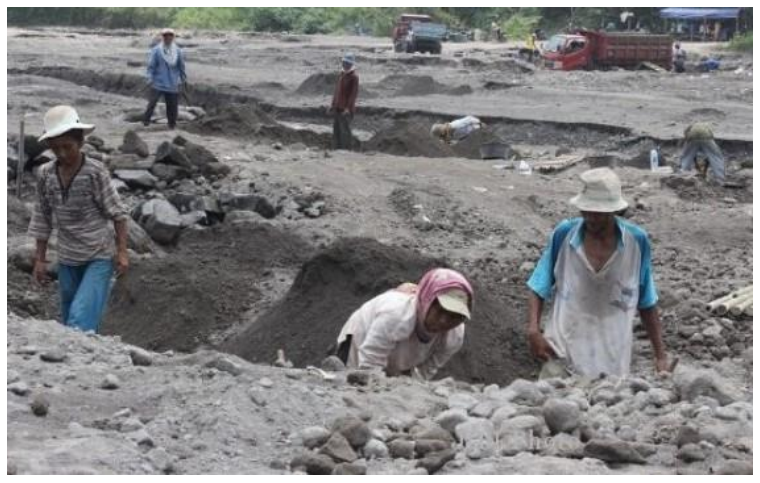

Gambar 3. Penggalian pasir menggunakan tenaga manusia (non mekanis)

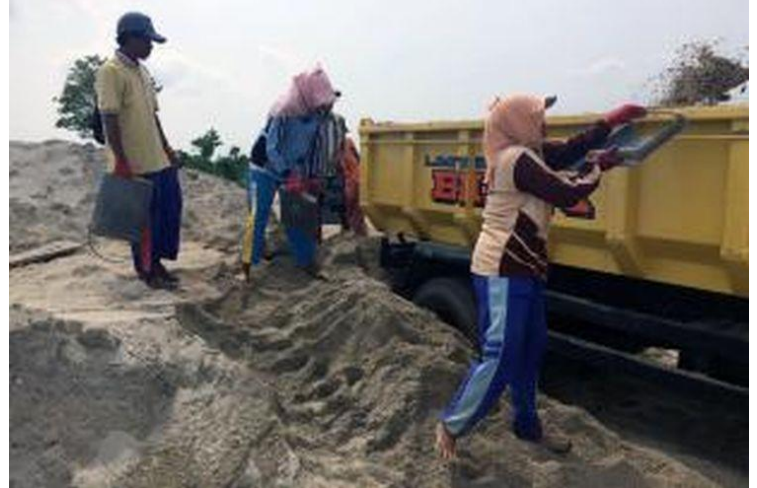

Gambar 4. Pemuatan pasir ke atas truk secara non mekanis 
Tim pengabdian dari Prodi Teknik Pertambangan Universitas Nusa Cendana yang melakukan survey ke lokasi penambangan pasir di Sungau Noelmina mengamati banyak permasalahan dan dampak dari penambangan yang terjadi di kelompok penambang pasir di lokasi tersebut, baik pada kelompok yang dikelola dengan cara mekanis maupun menggunakan tenaga manusia (non mekanis). Permasalahan dan dampak tersebut secara umum menyangkut masalah teknis produksi, masalah lingkungan, masalah sosial-ekonomi masyarakat, sistem manajemen usaha. Perusahanperusahaan tersebut telah lama beroperasi dan memberikan dampak positif bagi para pekerja sekitarnya seperti dengan berkembangnya inovasi dan kreasi masyarakat sekitar yang memanfaatkan pasir untuk menghasilkan produk kerajinan seperti pot tanaman, batako, ornamen taman dan sebagainya. Namun ada beberapa dampat negatif akibat aktifitas penambangan yaitu polusi udara. Terjadinya peningkatan debu menyebabkan kualitas udara di sekitar kawasan penambangan diakibatkan dari kendaraan truk yang mangangkut pasir serta tiupan angin. Suhu lingkungan area tambang terasa lebih panas karena vegetasi yang berada lokasi tambang telah rusak dan mati, ataupun ditebang untuk memudahkan penambangan dan bergeraknya alat muat dan alat angkut.

CV. Talenalain merupakan salah satu kelompok penambang pasir non mekanik dengan memperkerjakan masyarakat sekitar untuk mengumpulkan pasir dan dimuat ke truk secara manual (tenaga manusia). Mereka dibayar oleh pemiliki tambang berdasarkan volume material pasir yang telah mereka kumpulkan. Para pekerja ini menggali pasir menggunakan linggis, pacul dan sekop disekitar aliran sungai. Mereka bekerja mulai jam 8 pagi sampai jam 11 siang dan dilanjutkan kembali mulai jam 15 sampai jam 18. Mereka bekerja tanpa menggunakan Alat Pelindung Diri (APD) seperti helm, masker, tanpa alas kaki/sepatu dan sarung tangan. Pola waktu kerja yang panjang dan lokasi bekerja yang tidak steril telah memunculkan berbagai penyakit. Kebanyakan penambang bekerja pagi-pagi sekali dan selesai siang atau sore hari. Pekerjaan mereka tidak lepas dari berendam dalam air. Rosamia (2015) dan Jannah (2017) mengidentifikasi beberapa jenis resiko penyakit yang dapat timbul saat penggalian dan pemuatan ke atas truk, yaitu penyakit kadas, kurap, kutu air, varises, dan kapalan, keseleo, kulit tergores. Informasi insiden kecelakaan yang dialami para pekerja saat menambang dan memuat pasir. Akibat kecelakaan tersebut menyebabkan ketidakhadiran pekerja selama beberapa hari untuk memulihkan kesehatannya dan perusahaan seringkali memberikan bantuan untuk biaya pengobatan karena para penambang tidak memiliki asuransi kesehatan dan biaya untuk berobat. Target penambangan $800 \mathrm{~m}^{3}$ perbulan sering tidak tercapai sehingga tidak ada pasir yang dapat dimuat saat konsumen datang hendak membeli pasir. Kaligis (2013) menjelaskan bahwa kecelakaan kerja dan penyakit akibat kerja dapat membuat produktifitas kerja dari pekerja menurun, tingkat ketidakhadiran tinggi, intensitas kerja menurun. Melalui implementasi program Keselamatan dan Kesehatan Kerja (K3) ternyata dapat meminimalkan resiko kecelakaan dan penyakit akibat kondisi kerja. Berdasarkan semua permasalahan umum tersebut maka dipilih prioritas yang perlu segera ditindaklanjuti secara cepat di CV. Talenalain yaitu masalah target produksi yang tidak tercapai dan masalah K3. Hasil pengamatan dan wawancara awal didapatkan data analisis situasi sebagai berikut :

1. Usia karyawan bervariasi, umur termuda 17 dan yang paling tua berumur 55 tahun. Namun kebanyakan masih berusia antara 20 sampai 35 tahun.

2. Tingkat pendidikan pekerja rata-rata tidak selesai sekolah dasar dan sekolah menengah pertama dan ada juga yang tidak pernah sekolah.

3. Persentase karyawan yang mengalami sakit dan kecelakaan di CV. Talenalain seperti pada Tabel 1. Penyakit yang timbul dan pernah dialami oleh semua 
pekerja adalah penyakit gatal-gatal akibat kutu air, tangan melepuh dan lecet, terpapar suhu panas dari matahari, sakit kepala dan keseleo (persentase 100\%).

Tabel 1. Jenis Aktifitas yang berpotensi Kecelakaan

\begin{tabular}{lll}
\hline No & Jenis Aktivitas dan Potensi Kecelakaan & Persentase \\
\hline I & Penggalian pasir & \\
\hline & 1. Terbawa arus sungai & $10 \%$ \\
& 2. Terkena kutu air, dan penyakit gatal-gatal & $100 \%$ \\
& 3. Terpeleset & $50 \%$ \\
& 4. Terjatuh, terjerumus lubang galian & $30 \%$ \\
& 5. Tangan melepuh, lecet, kapalan & $100 \%$ \\
& 6. Batuk dan sesak nafas akibat debu & $50 \%$ \\
& 7. Luka pada kaki terkena batu tajam, beling, paku, duri & $40 \%$ \\
& 8. Luka terkena benturan sekop, pacul, linggis & $20 \%$ \\
& 9. Kulit memerah akibat terpapar suhu panas matahari & $100 \%$ \\
& 10. Telinga kemasukan air, tidak sengaja meminum air kotor & $30 \%$ \\
& 11. Kemasukan debu/pasir ke mata & $20 \%$ \\
& 12. Sakit kepala, pinggang/punggung, terseleo & $100 \%$ \\
\hline II & Memuat Pasir ke atas truk & $20 \%$ \\
& 1. Terpeleset & $100 \%$ \\
\hline
\end{tabular}

Masalah K3 selalu dianggap masalah remeh oleh para pekerja bahkan bagi perusahaan dianggap sebagai beban biaya tambahan operasional, padahal keselamatan dan kesehatan pekerja harus mendapat perhatian karena telah diatur pula dalam Undang-undang No 1 Tahun 1970 yang mengatur mengenai Keselamatan dan Kesehatan Kerja. Maksud dari keselamatan kerja adalah untuk menentukan standar yang jelas untuk keselamatan kerja bagi semua karyawan sehingga mendapatkan perlindungan atas keselamatannya saat melakukan pekerjaannya, meningkatkan kesejahteraan hidup, meningkatkan produksi serta produktifitas nasional, memberikan dasar hukum agar setiap orang yang berada di tempat kerja terjamin, dan sumberdaya yang dipakai dapat dipergunakan secara aman dan efisien sesuai norma kerja yang sesuai dengan perkembangan masyarakat, industrialisasi, teknik dan teknologi. Sedangkan maksud kesehatan kerja adalah upaya untuk mencegah dan memberantas penyakit serta memelihara dan meningkatkan kesehatan gizi para tenaga kerja, merawat dan meningkatkan efisiesi dan daya produktifitas tenaga manusia. Kesadaran K3 perlu ditumbuhkan kepada pemilik perusahaan dan para pekerja tambang sirtu tersebut. Latar belakang pendidikan yang sebagian besar tidak sempat bersekolah atau tidak bisa melanjutkan pendidikan dan kurangnya informasi pengetahuan tentang pentingnya K3 yang akan menyebabkan meningkatnya resiko kecelakaan dalam bekerja. Bayu (2013) menjelaskan adanya hubungan faktor-faktor yang berhubungan dengan kecelakaan kerja terhadap kondisi pekerja seperti umur, masa kerja, perilaku berbahaya, kondisi lingkungan sehingga dapat menyebabkan kecelakaan kerja. Manajemen resiko kerja diatur berdasarkan ISO 3100-2009. Penilaian resiko merupakan kombinasi likelihood dan severity dari suatu kejadian yang membahayakan terjadi (Hasbi 2015).

Pencegahan kecelakaan kerja harus dilakukan melalui suatu perencanaan dan usaha yang terus menerus melalui pemantauan/pengawasan agar timbul kesadaran pekerjaa untuk mentaati rambu-rambu keselamatan kerja. Menurut Suma'mur (2009) ada 4 faktor penyebab kecelakaan kerja yaitu faktor manusia, faktor alat/mesin, faktor material yang ditangani, dan lingkungan kerja. Sedangkan bahaya yang dapat timbul dari suatu pekerjaan dapat dianalisis berdasarkan sumbernya yaitu proses produksinya, material/bahan yang digunakannya, jenis kegiatan pekerjaan yang dilakukan, serta 
instalasi yang mengandung potensi bahaya (Soehatman, 2010). Menurut UU No 23 Tahun 1992 memberikan ketentuan tentang Kesehatan, dimana dalam Pasal 23, menyebutkan bahwa kesehatan kerja dilaksanakan supaya semua pekerja dapat bekerja dalam kondisi kesehatan yang baik tanpa membahayakan diri mereka sendiri atau masyarakat, dan supaya mereka dapat mengoptimalkan produktivitas kerja mereka sesuai dengan program perlindungan tenaga kerja. Kecelakaan selalu ada penyebabnya, dan cara penggolongan sebab-sebab kecelakaan diberbagai negara juga tidak sama. Namun secara umum, sebab-sebab kecelakaan kerja dapat digolongkan menjadi kondisi yang tidak aman (unsafe condition) dan tindakan yang tidak aman (unsafe action) (Rolan, 2020).

Pasal 140 Ayat 3, UU No. 4 Tahun 2009 dan Kepmen No.1453.K/29/29/MEM/ 2000. Tentang PedomanTeknis Penyelenggaraan Tugas Pemerintahan di Bidang Pertambangan pada Bab V tentang Pembinaan dan Pengawasan menjelaskan bahwa pelaksanaan pembinaan dan pengawasan usaha pertambangan umum terhadap para pemegang Kuasa Pertambangan, Kontrak Karya dan PKP2B dilakukan oleh Menteri ESDM, Gubernur, Bupati atau Walikota sesuai lingkup kewenangan masing-masing. Pembinaan dan pengawasan meliputi aspek lingkungan, konservasi, tenaga kerja, barang modal- jasa pertambangan, penerapan standar pertambangan, investasi dan divestasi, keuangan. Pelaksanaan pengawasan lansung di lapangan dilaksanakan sekurangkurangnya enam bulan sekali (Thabri, 2004).

Perguruan tinggi wajib pula mengawasi pelaksanaan K3 dalam rangka memberikan pendidikan kepada masyarakat dalam hal keselamatan kerja saat melakukan penambangan pasir dan pembinaan kepada perusahaan pemilik tambang agar mampu menganalisis potensi kecelakaan serta menyiapkan sarana prasana pencegahan kecelakaan pada aktivitas usahanya. Tujuan pengabdian masyarakat mengenai pelaksanaan K3 di perusahaan tambang pasir ini adalah untuk mencegah terjadinya penyakit yang persentasenya dialami oleh seluruh pekerja yaitu penyakit gatal akibat kutu air, tangan yang melepuh dan kapalan, kulit yang memerah, sakit kepala, dan pinggang yang keseleo. Sedangkan untuk menurunkan kecelakaan kerja maka perlu pembinaan operasional penambangan yang aman dan sesuai dengan motto safety first dalam dunia pertambangan yang nanti akan berdampak pada meningkatnya produksi penambangan.

\section{METODE}

Kegiatan pengabdian masyarakat di CV. Talenalain terbagi menjadi 3 tahapan kegiatan, Tahapan I yaitu tahapan permintaan izin melaksanakan kegiatan dari Kantor Kecamatan dan Kantor Desa (Gambar 5). Setelah itu dilaksanakan penentuan permasalahan di lapangan dengan menggunakan metode pengamatan langsung pada aktivitas penambangan di Sungai Noelmina, melakukan wawancara secara khusus dengan pimpinan CV. Talenalain untuk mendapatkan kondisi produksi perusahaan selama beberapa bulan sebelum kegiatan pengabdian (April, Mei, Juni), fasilitas kerja yang disediakan perusahaan, peraturan, kebijakan, manajemen perusahaan dalam implementasi K3 data jumlah pekerja, usia rata-rata, tingkat pendidikan serta jenis-jenis penyakit serta jenis-jenis penyakit dan kecelakaan yang sering dialami pekerja sehingga menyebabkan mereka tidak bisa beraktifitas sementara waktu. 


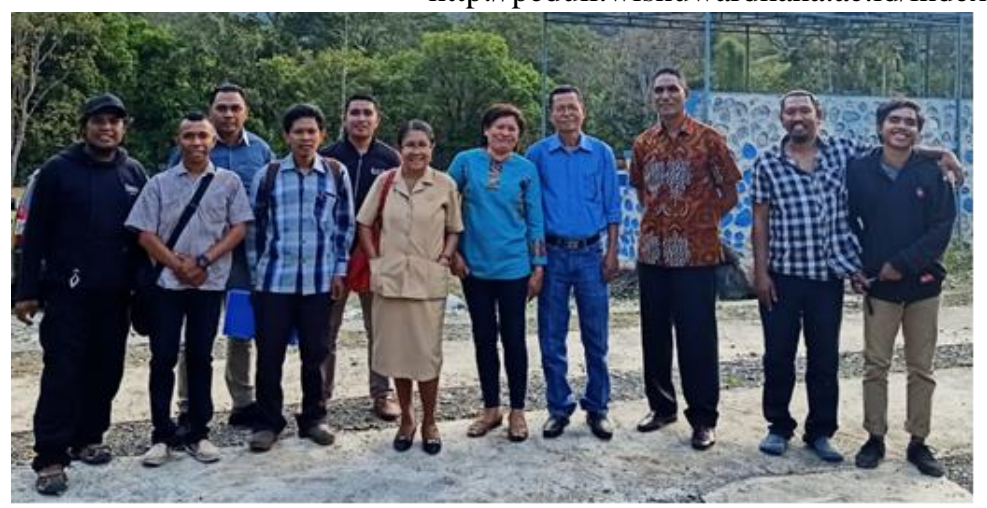

Gambar 5. Tim Pelaksana, Aparat Desa dan Pimpinan CV. Talenalain

Tahapan II adalah penyampaian materi mengenai Keselamatan dan Kesehatan Kerja sesuai dengan aktifitas yang dilakukan perusahaan. Materi-materi kegiatan disampaikan oleh narasumber dari Tim Pelaksana Kegiatan Pengabdian Masyarakat, aparat desa (Sekretaris Desa, Ketua Badan Permusyawaratan Desa dan Dinas Energi dan Sumber Daya Mineral (ESDM) Provinsi. Jumlah peserta sebanyak 25 orang yang semuanya merupakan karyawan Talenalain. (Gambar 6).

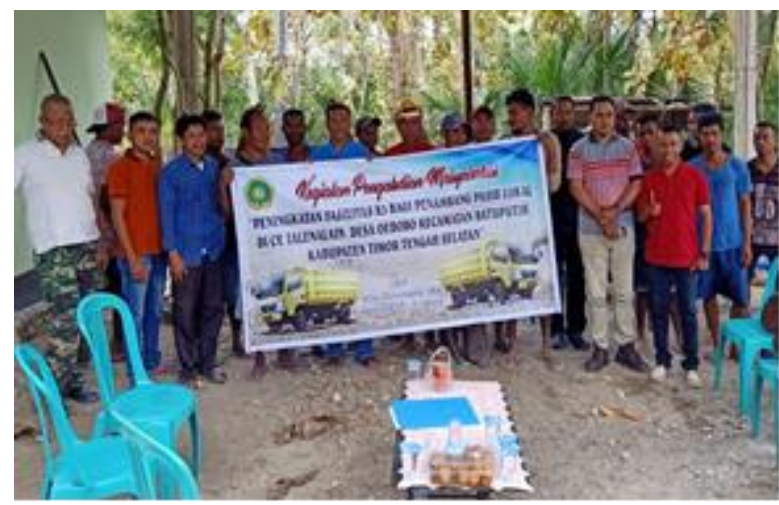

Gambar 6. Peserta Pelatihan K3 dari CV Talenalain

Pada tahap ini dijelaskan pengenalan dan manfaat Alat Pelindung Diri (APD), penjelasan mengenai kecelakaan yang dapat terjadi pada saat penambangan. Tim Pelaksana juga memberikan 25 set APD berupa helm kerja, sarung tangan dan masker (Gambar 7). Hal ini dilakukan sebagai upaya menjaga Kesehatan dan mencegah terjadinya kecelakaan kerja dan meningkatkan kesadaran para pekerja untuk melindungi diri secara mandiri.

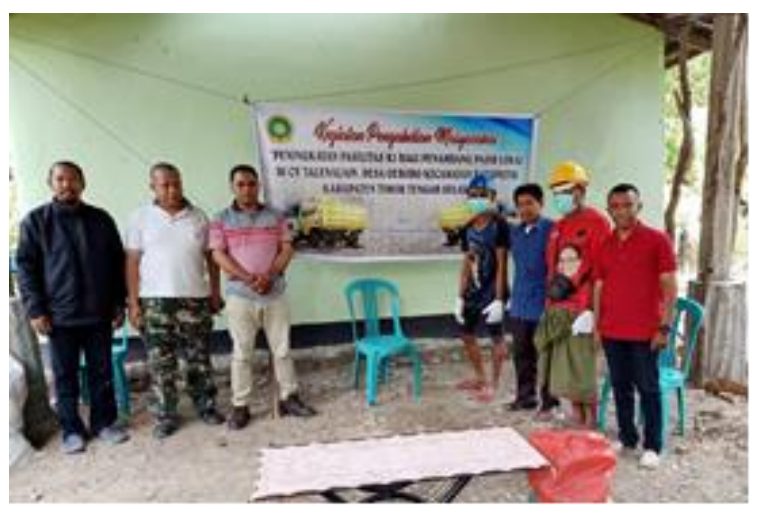

Gambar 7. Penyerahan dan pemakaian APD secara simbolis 
Tahap III merupakan tahapan untuk melakukan evaluasi dampak dari kegiatan Pengabdian terhadap produksi perusahaan dan insiden kecelakaan yang terjadi pasca pelaksanaan kegiatan pengabdian ini. Pada tahapan ini didapatkan data jumlah produksi yang dicapai perusahaan dan data kehadiran pekerja selama selama 5 bulan sejak mulai Bulan Juli sampai dengan Bulan Desember.

\section{HASIL KARYA UTAMA DAN PEMBAHASAN}

Kegiatan tahap II merupakan tahapan inti dari pengabdian masyarakat ini, dimana dilakukan penyuluhan mengenai K3 kepada seluruh karyawan. Agar tidak mengganggu produksi kerja maka dipilih pelaksanaanya pada hari Minggu selama 2 kali pertemuan. Pertemuan pertama merupakan pembukaan oleh sekretaris desa. Aparat desa sangat mendukung dan berharap kegiatan pengabdian mengenai K3 di CV. Talenalain dapat disampaikan pula ke perusahaan lain yang melaksanakan penambangan secara non mekanis. Pihak perusahaan juga berharap ilmu dari perguruan tinggi dapat menimbulkan kesadaran dan kemandirian pekerjaan untuk melengkapi APD sehingga tanpa fungsi pengawasan pun para pekerja tetap menggunakannya.

Materi pemaparan mengenai K3 yang disampaikan oleh Tim pelaksana pengabdian masyarakat sebagai berikut :

1. Menyampaikan potensi bahaya kecelakaan yang dapat terjadi pada lokasi penambangan pasir yang paling sulit dihindari adalah longsor, terutama penambangan yang dilakukan pada sisi tebing sungai. Meskipun kejadian longsor dari tebing belum pernah terjadi di Sungai Noelmina, namun perlu disampaikan potensi bahaya ini kepada para penambang yang seringkali tidak menyadari bahwa pasir bersifat material lepas (loose) yang akan menjadi tidak stabil bilamana mendapatkan beban, getaran dan terkena air. Para pekerja pada saat mengambil pasir tidak menyadari ketinggian dan kemiringan lereng penambangan seringkali sudah tidak memenuhi kriteria aman. Pada Gambar 8 menunjukkan contoh jenjang tegak lurus dan tinggi yang dapat ambruk setiap saat. Supaya front penambangan tetap aman adalah dengan membuat sistem berjenjang (bench), kemiringan lereng dibuat landai dengan sudut kemiringan kurang dari $30^{\circ}$, tinggi jenjang tidak lebih dari 3 meter. Namun pembuatan jenjang penambangan dengan tenaga manusia hal tersebut akan sulit dilaksanakan, sehingga pada penambangan di sisi sungai semestinya menggunakan alat-alat berat, dan masyarkat dilarang menggali di bawah tebih yang tegak lurus.

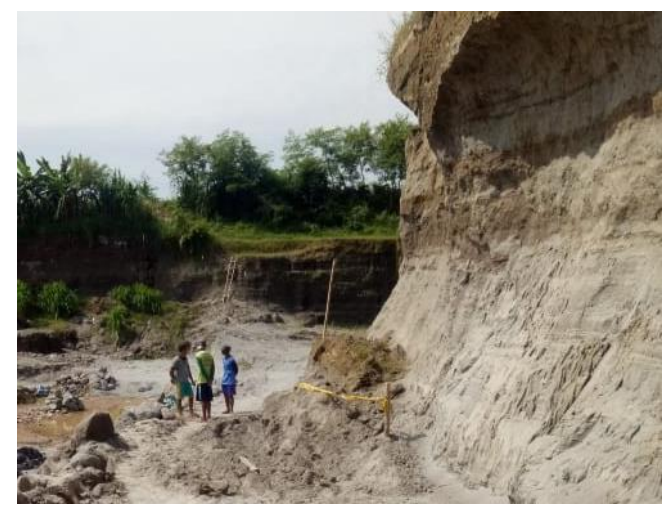

Gambar. 8. Tebing pasir tegak lurus dan ketinggian yang sangat tidak aman

Selain bahaya longsoran adalah bahaya terperosoknya pekerja pada lubanglubang bekas galian yang seringkali telah terisi oleh air sungai (Gambar 9.). Kedalaman lubang bekas galian sulit diperkirakan bila telah terisi oleh genangan air. 
Selain itu membahayakan kendaraan truk yang melintas untuk memgangkut pasir. Upaya untuk menghindarinya adalah menggunakan tongkat penanda kedalaman lubang yang telah terisi air atau membuat batas pengaman menggunakan tali atau kayu atau menggunakan papan peringatan adanya lubang galian sehingga kendaraan atau pekerja dapt menghindarinya.

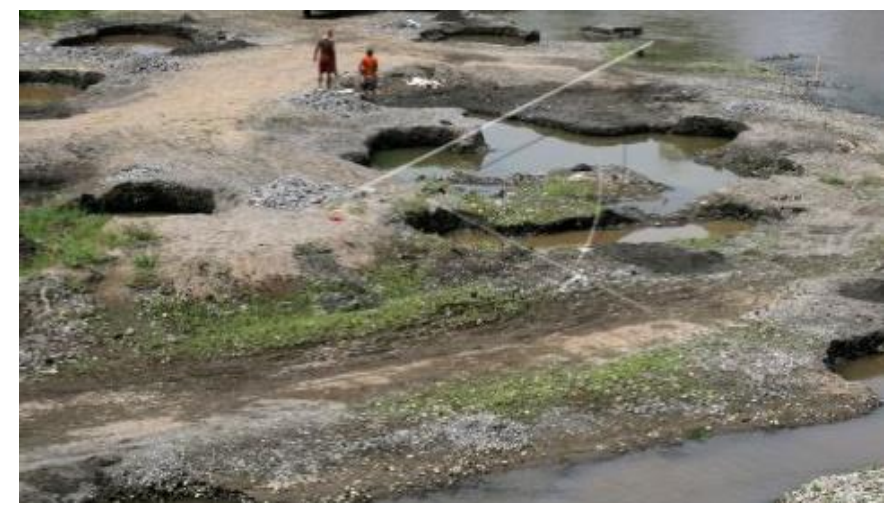

Gambar 9. Lubang bekas penggalian yang telah terisi air sungai

2. Menjelaskan beberapa jenis penyakit yang dapat timbul dan mengganggu kesehatan. Timbulnya penyakit gatal di kaki akibat kutu air dan jamur dapat diatasi dengan menggunakan sepatu karet, namun hal tersebut sulit dilakukan karena terkadang air sungai juga tetap masuk ke dalam sepatu, terlebih jika kondisi sedang hujan atau gerimis. Para pekerja dihimbau untuk membersihkan kaki setelah selesai bekerja dengan sabun dan bila terjadi gatal segera diobati dengan salep anti jamur. Penggunaan sepatu juga dapat mencegah pekerja terpeleset atau menginjak duri dan paku di lokasi tambang. Kulit memerah akibat terpapar matahari dapat diatasi dengan menggunakan pakaian berlengan panjang dan menutup leher dan muka agar terlindung dari matahari. Para penambang juga diberi arahan posisi tubuh saat menggali menggunakan sekop (Gambar 10 A) dan pacul (Ganbar 10 B) agar terhindar sakit keselo punggung.

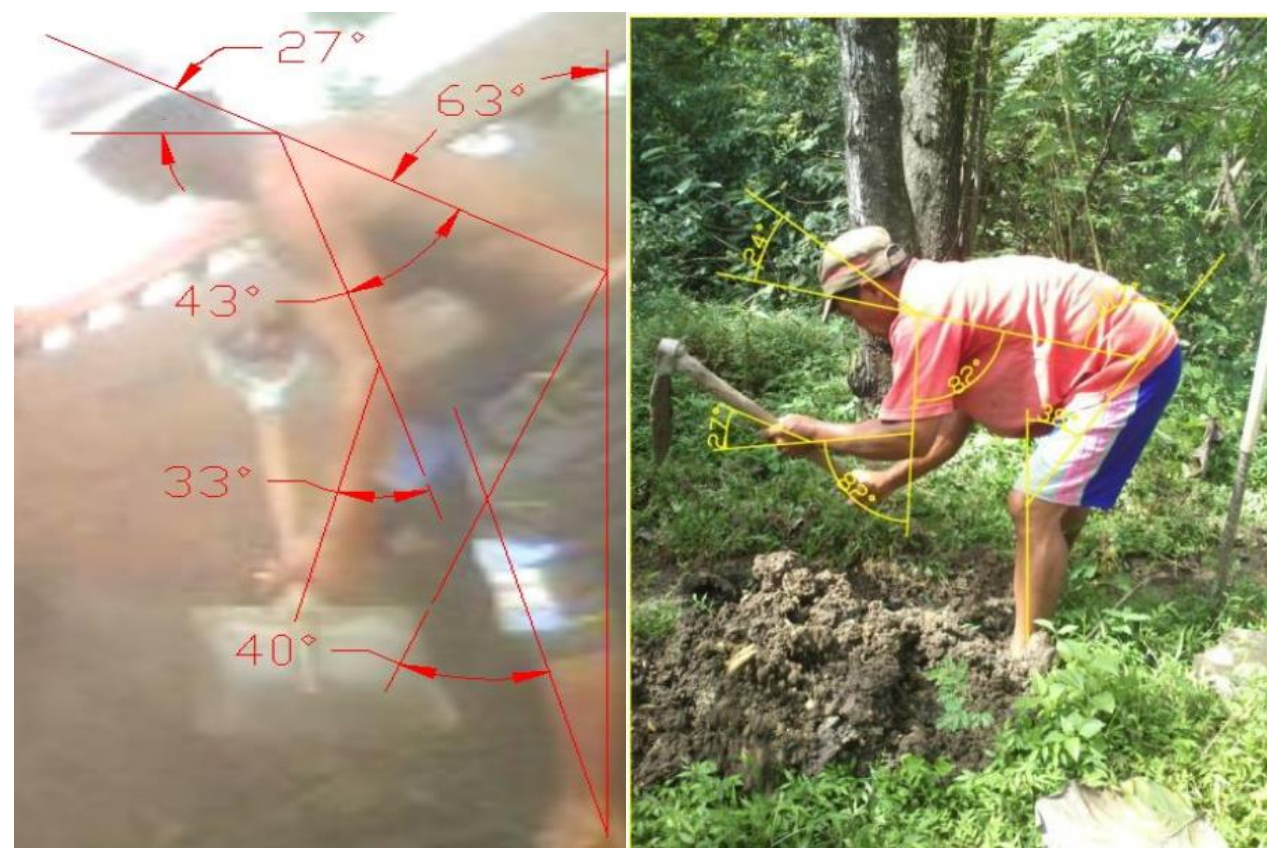

A. Menggali dengan sekop
B. Menggali dengan pacul

Gambar 10. Posisi tubuh saat melakukan penggalian 
3. Pengenalan Alat Pelindung Diri (APD) yang digunakan harus sesuai standar keamanan saat bekerja seperti pada Gambar 11. Fungsi helm untuk melindungi kepala dari benturan alat gali dan bahaya jatuh material batu dari atas, menghindari panas matahari secara langsung pada kepala, masker untuk melindungi organ pernafasan dari paparan debu, sarung tangan untuk melindungi tangan pekerja agar tidak lecet saat memegang alat gali, kacamata pengaman untuk mencegah masuknya partikel pasir ke mata, dan sepatu untuk pelindung kaki.

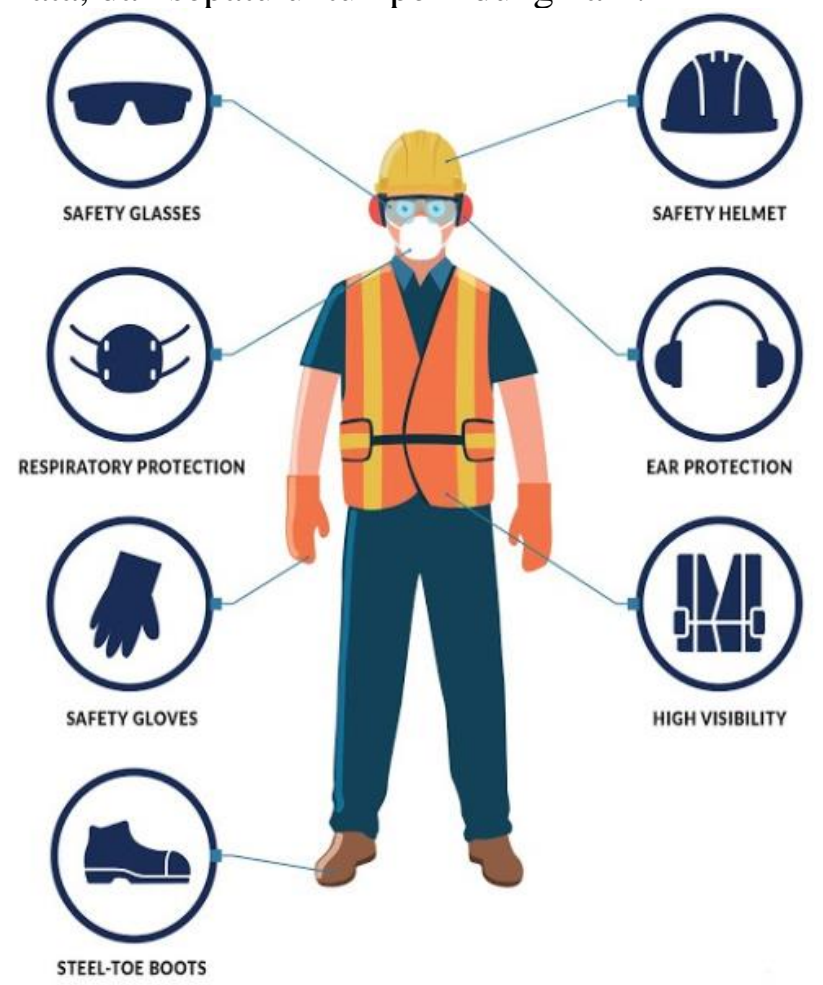

Gambar. 11. Alat Pengaman Diri (APD) yang sesuai Standar K3

4. Pemberian materi khusus berupa penjelasan mengenai kumpulan peraturan mengenai K3 kepada pihak perusahaan seperti isi UU , Peraturan Pemerintah, Peraturan Menteri, Keputusan Menteri, Instruksi Menteri, Surat Edaran dan Keputusan Dirjen Pembinaan dan Pengawasan K3. Berdasarkan landasan hukum tersebut maka perusahaan diharuskan :

- Memeriksa kondisi pekerja pada saat pertamakali diterima

- Memeriksa kesehatan karyawan secara berkala dan pemeriksaan secara khusus

- Menyediakan obat yang cukup untuk Pertolongan Pertama pada Kecelakaan (P3K)

Sedangkan upaya untuk mencegah kecelakaan di lokasi penambangan maka perusahaan wajib :

- Memberi sanksi dan tidak mengijinkan kepada karyawan yang akan masuk tanpa menggunakan APD

- Memberikan rambu-rambu peringatan akan bahaya kerja

Pada kegitan tahap III dilakukan wawancara kembali dengan pimpinan perusahaan untuk mengetahui hasil dari penerapan K3 terhadap produktifitas penggalian dan kehadiran pegawai. Hasil tersebut ditampilkan pada Gambar 12. 


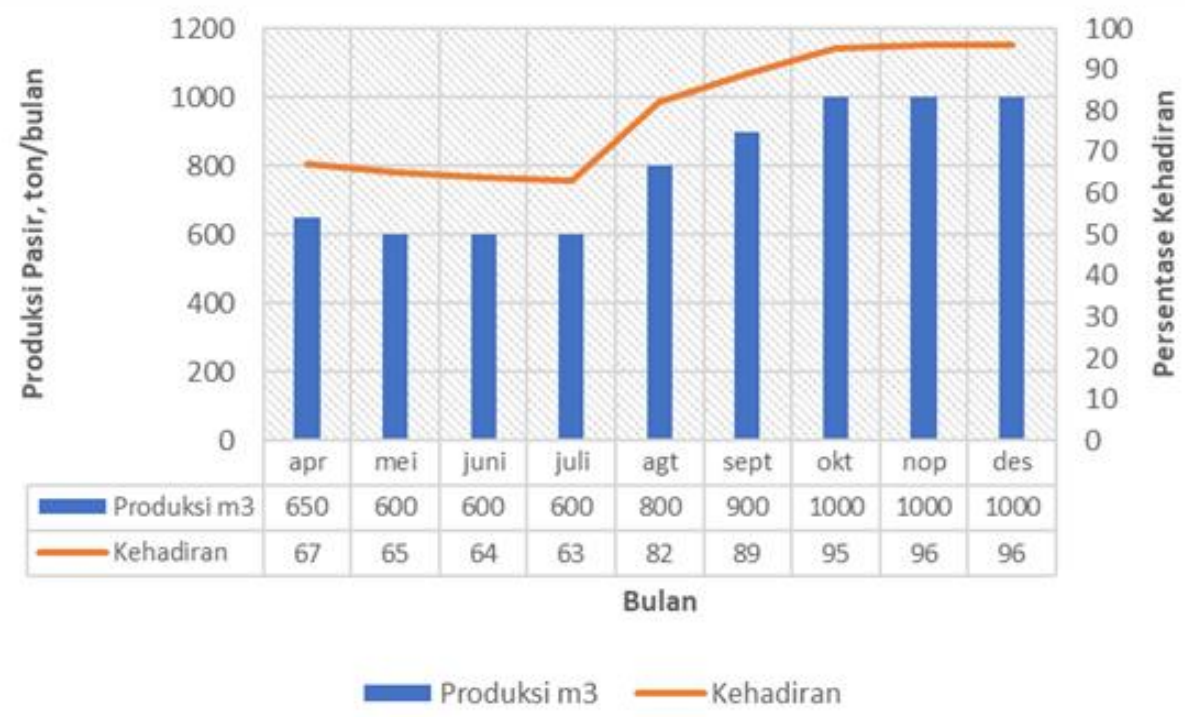

Gambar 12. Peningkatan Produksi dan Kehadiran para pekerja

Target produksi pada bulan April sampai bulan Juli tidak terpenuhi sebesar $1000 \mathrm{~m}^{3}$ (meter kubik) setiap bulannya bahkan terus menurun sampai bulan Juli hanya sebesar 600 kubik. Hal ini karena karyawan yang hadir hanya kisaran 63\% sampai $67 \%$ yang yang tidak hadir dengan alasan sakit (terkilir, sakit pinggang, sakit kepala, dan lain sebagainya). Setelah dilakukan pendampingan penjelasan manfaat K3 maka mulai terjadi peningkatan produksi sejak Agustus sampai Desember dan dapat memenuhi target $1000 \mathrm{~m}^{3} / \mathrm{bulan}$

\section{KESIMPULAN}

Tingkat kecelakaan pada tambang pasir memang relatif jarang terjadi. Tidak tercapainya produktifitas cenderung dikarenakan ketidak hadiran pekerja dengan alasan sakit. Kegiatan pengabdian masyarakat berupa Pendampingan K3 di CV. Talenalain dapat menurunkan penyakit yang timbul akibat bekerja di penambangan pasir. Dengan berkurangnya frekuensi pekerja yang sakit menyebabkan peningkatan kehadiran pekerja mencapai $96 \%$ yang pada akhirnya dapat meningkatkan produktifitas produksi penambangan pasir sebesar $20 \%$. Ketaatan pekerja dalam mengenakan APD mencapai $80 \%$.

\section{UCAPAN TERIMAKASIH}

Tim Pelaksana mengucapkan terima kasih kepada Dekan Fakultas Sain dan Teknik Undana yang telah memberi dukungan finansial dan penugasan terhadap kegiatan pengabdian ini dengan SPK Pengabdian Nomor 109/UN15.12.PPK/SPP/FST/IV/ 2019 tanggal 05 April 2019.

\section{DAFTAR PUSTAKA}

Suma'mur, 2009, Keselamatan Kerja dan Pencegahan Kecelakaan, PT. Gunung Agung, Jakarta.

Soehatman, 2010, Manajemen Resiko dalam Perspektif K3 OHS Risk Manajemen, PT. Dian Rakyat, Jakarta.

Bayu W (2013). Faktor-Faktor Yang Berhubungan Dengan Kejadian Kecelakaan Kerja Pada Pekerja Tambang Pasir Gali Di Desa Pegiringan Kabupaten Pemalang http://eprints.dinus.ac.id/8009/1/jurnal_13981.pdf 
Hasbi I., dkk, 2015, Analisis Potensi Bahaya dan Penilaian Resiko Pada Area Quarry PT. Semen Bosowa, Jurnal Al Sihah, Public HealthScience Journal, Vol. VII, hal 215-222.

Raldo S.V. Kaligis, dkk, 2013. Pengaruh Implementasi Program Keselamatan dan Kesehatan Kerja (K3) Terhadap Produktifitas Kerja, Jurnal Sipil Statik Vol.1,No.3.Februari 2013.

Rolan K., Rijal A. Faktor Penyebab Terjadinya Kecelakaan Kerja Pada Area Penambangan Batu Kapur Unit Alat Berat Pt. Semen Padang, Jurnal Bina Tambang, Vol 5, No 2. http://103.216.87.80/index.php/mining/article/view/107814

Samsul, dkk, 2018, Analisis Dampak Positif Industri Terhadaplingkungan Masyarakat, Jurnal Geomine,Vol.6,No2: Agustus. https://jurnal.teknologiindustriumi.ac.id/index. php/JG/article/view/209/177

Rosamia B.A.A., Ma'rufi I., Sujoso A.D.P. (2015), Analisis Risiko Keselamatan dan Kesehatan Kerja di Penambangan Pasir Kabupaten Lumajang, Artikel Ilmiah Hasil Penelitian Mahasiswa, http://repository.unej.ac.id/bitstream/handle/123456789/ 69243/ Bernadzar\%20Asha\%20Army\%20Rosamia.pdf?sequence=1

Jannah E.M., Alfirosa B.P. Analisis Risiko Keselamatan Dan Kesehatan Kerja pada Pekerja Penambang Pasir Sungai Di Daerahjembatan Korek, Andongsari-Ambulu, Kabupaten Jember https://www.academia.edu/35409453/Analisis_Risiko_K3_Pada Pekerja Penambang_Pasir_Sungai

Thabrie A., 2004, Diklat Pertambangan Terbuka ; UU dan K3 Pertambangan http://investasibisnis.weebly.com/uploads/8/4/9/7/8497185/undangundangk3pertam bangan.pdf 